\title{
Un narrador insolidario: el caso de Jinta de acreedores de Julio Ramón Ribeyro
}

\author{
Jorge ValenzUELAa Garcés \\ Universidad Nacional Mayor de San Marcos
}

$\&$

\section{Resumen}

Se analiza al narrador en el cuento "Irnta de acreedbres" de Julio Ramón Ribeyro incluido en su primer libro Los gall inazos sin plumas. Nuestro propósito es probar que, por lo menos, en este cuento, el autor se aleja de la prédica neorreal ista que la crítica le ha atribuido hasta ahora. Cuestionando este lugar comín, proponemos una mueva lectura que descubre en el texto la defensa implícita de un sistema que valora positivamente la fortaleza de aquellos que saben adaptarse al cambio, frente a los que son vistos como incapaces de tal adaptación (las llamadas víctimas sociales reivindicadas por los neorrealistas) . Finalmente se trabaja con un concepto que críticos como James Higgins utilizan para juzgar los cuentos de Ribeyro: la inhumanidad del sistema. Aquí doservamos cómo este concepto entra en crisis al ser aplicado al cuento, sobre toob arando constatamos que en él, a través del narrador, hay una burla irónica contra el comportamiento de los más débiles.

Palabras claves: Ribeyro, neorrealismo, narrador, inhumanidad del sistena.

\section{Introducción}

7 unque el neorrealismo es primero una manifestación literaria, en A el caso de las influencias que afectan a la narrativa peruana de los cincuenta, debemos hablar de una impronta neorrealista proveniente 
del cine italiano de la época (Delgado 1995). Los temas que tratan tanto el cine como la literatura neorrealista no son, en esencia, diferentes, pero filmes como Obsesión (1942) , partida de nacimiento del movimiento, Roma, ciudad abierta (1945) o Ladrón de bicicletas (1948) , serán decisivas en la formación ideológica y sentimental de escritores como Ribeyro, Zavaleta o Congrains. Por ello debemos asumir que desole el cine la prédica neorrealista ejerció una importante influencia sobre nuestra literatura narrativa a través de su explícito tratamiento moral de las contradicciones generadas después de la Segunda Guerra Mundial.

El neorrealismo, según García Escudero (1970: 125), es una demuncia de la insolidaridad humana, una protesta contra aquello que niega los valores que, precisamente, humanizan al hombre. Según Zavattini, uno de los principales guionistas del movimiento, el neorrealismo supone mirar solidaria y amorosamente al ser humano, lo que lo convierte en una estética que privilegia la atención social. En su artículo Tesis sobre el neorrealismo, sostiene, además, que en "el descubrimiento de la actualidad" residen los intereses del movimiento y que su actitud, por humana, es "antirretórica, situada decidida y polémicamente contra la hipocresía de la opresión del fascismo" . (Romaguera y Ramió: 209) . El neorrealismo es, por lo tanto, un movimiento estético que, en el contexto de la guerra y la postguerra, buscó sensibilizar al espectadbr con respecto a su propio medio social, medio en el que, como lo muestran tanto los filmes como los relatos, es visible advertir las contradicciones propias de un contexto de crisis generalizada.

El neorrealismo, además, se aparta del realismo decimonónico en tanto aquella imprescindible mirada solidaria le permite observar comprensivamente al ser humano, sin censuras y sin condenarlo por sus actos o condición social.

\section{El neorrealismo y la narrativa de Julio Ramón Ribeyro}

Para un crítico como Higgins (1991), Ribeyro es un escritor neorrealista porque en sus cuentos se observa el tratamiento de una 
serie de contradicciones propias de un contexto de posguerra, pero sobre todb lo es porque en su narrativa se doservaría la representación de un momento de crisis (el nuestro) marcado por el tránsito de una sociedad tradicional a otra en vías de modemización (1991: 15). Ese, pues, sería según Higgins, entre otros, un valor importante de su narrativa; esa, ademés, la forma en que los escritores del cincuenta y, especialmente Ribeyro, procesaron la "crisis" del sistema.

Tenemos, entonces, por un lado, una denuncia de la insolidaridad humana como uno de los principios básicos del neorrealismo y, por otro, un contexto (el limeño) en el que se produce un violento proceso de modernización. ¿Cómo es que estas dos coordenadas armonizan (si es que armonizan) en la narrativa de Ribeyro y, sobre todo, qué medios son los utilizados por el autor para conseguir su propósito?

Para el caso del análisis de los cuentos de Ribeyro debemos, en principio, atender el hecho de que existen dos modos bastante diferenciados de ser neorrealista: el primero, abiertamente marxista y crítico y, el segundo, limitadb, según los especialistas, a "representar la realidad". Entre nosotros fue esta última vertiente la que tuvo más éxito y ejercicio y la que, por lo menos en el caso de un escritor como Ribeyro, es más visible.

Es importante señalar que el neorrealismo se construye políticamente en oposición al fascismo y que, estéticamente, su estrategia dbamental y verista es el correlato inevitable de la necesidad de mostrar un horizonte social doturado por el totalitarismo y la guerra. De ahí que sea pertinente estudiar los modos en que la prédica neorrealista es asumida por nuestros narradores y también las consecuencias que eso desencadena en su práctica con la escritura.

Si partimos del hecho de que los cuentos de Ribeyro no son explícitamente marxistas y que no se generan en un contexto vinculado directamente con la destrucción de la posguerra, valdría la pena formular alguna hipótesis que nos permita determinar la naturaleza de la variante que la narrativa de Ribeyro abre con su particular manejo. Variante que, sostenemos, es posible observar en aquellos cuentos que se alejan de la ortodoxia neorrelista y que, más bien, muestran a un escritor incómodo con ese tipo de humanismo bien intencionado. La idea es observar las consecuencias de esa incomodidad, los 
resultados de esa renuncia que llega a la ironía y hasta el sarcasmo contra las llamadas "víctimas sociales" del sistema.

Nuestra hipótesis sostiene que la posición del narrador instrumentado por Ribeyro en el cuento "Junta de acreedores" es, con respecto a la ortodoxia neorrealista, insolidaria. Creemos que el cuento instaura situaciones en las que el narrador adopta ciertas actitudes ideológicas ajenas a los valores que la escuela neorrealista pregonaba, estableciendo una crítica y un distanciamiento irónicos.

\section{2 ㅌll narrador en "Uunta de acreedores"}

\section{1. ¿th narrador solidario en "Ulunta de acreedores"?}

Empecemos definiendo al narrador como aquella entidad a la que "le cabe la tarea de enunciar el discurso" de la narración (Reis 1996: 156). Pero, fundamentalmente como aquella entidad en la que el enunciatario puede proyectar "ciertas actitudes ideológicas, éticas, culturales, cultivando, eventualmente, estrategias ajustadas a la representación artística de esas actitudes: ironía, aproximación parcial, construcción de un alter ego" (Reis 1996: 157) . El narrador es poseedor de una voz a través de la cual se vincula con una instancia de enumciación del discurso que puede materializarse en una determinada situación narrativa (Reis 1996: 157). En el caso de cuento citado estamos frente a un narrador situado fuera de la diégesis (una vez que no integra ni ha integrado, como personaje, el universo de la narración) (Reis 1996: 160) pero que, a través de un manejo singular de esa ubicación, establece ciertos vínculos afectivos con la materia narrativa.

El narrador heterodiegético se ha entendido tradicionalmente como un tipo de narrador que establece una relación polar entre sí mismo y el universo narrado. Reis (1996) establece que esta relación es, en principio, irreductible; lo que, además, le permitiría desarrollar un actitud demiúrgica y lograr, dentro del relato, una autoridad que no se cuestiona.

Desde esta situación narrativa, el narrador configura el universo de la narración. 
Una de las primeras constataciones que pueden realizarse cuando uno doserva al narrador en la serie de cuentos Ios gallinazos sin plumas (1955) y específicamente en "Junta de acreedores", es que éste se ha construido para evitar que, a través de él, se filtre información innecesaria o de explícita intención moralizante. Fl narrador construido está pensado para que, a través de él, se administre, un determinado tipo de información. ¿Qué tipo de información es la que el narrador nos brinda? Una información concisa, puntual, económica y alejada de excesos sentimentales o dramáticos y, sin embargo, estrechamente vinculada a ciertos destinos infaustos, a ciertas trayectorias marcadas por el fracaso, la muerte y la destrucción. Digamos, a partir de la observación del funcionamiento del narrador, que éste privilegia la focalización interna en sus personajes y que de esta manera controla cualquier exabrupto, cualquier extralimitación que pudiera generarse desde el ámbito de sus pareceres.

Ia segunda constatación es que el narrador de Ribeyro es un narrador cuyas reacciones y percepciones se producen frente al estímulo de relaciones interpersonales degradadas. Quien percibe ha elegido narrar las relaciones que se establecen entre los sujetos en condiciones marcadas por el dominio y la subordinación o sumisión. El narrador está entrenado en la descripción de las relaciones de poder y en las consecuencias que estas relaciones tienen sobre los destinos de los personajes. Es un narrador que fundamentalmente describe y, en el ejercicio de la descripción de los comportamientos y sentimientos, lo que quiere es mostrarle al lector un conocimiento de los seres humanos marcados por un contexto desfavorable.

El escenario para el funcionamiento de este narrador y de estas relaciones puede ser natural, como en "Mar afuera", pero lo usual es que sean espacios pertenecientes a la ciudad. En este caso, así como las relaciones representadas, el espacio está marcado por la degradación. Por ello quien narra elige corralones, basureros, callejones, bares o bodegas en bancarrota, como si en esos espacios se pudiese diagnosticar mejor los cambios que se operaban en esos años en el Perú.

Efraín Kristal (1984: 129) sostiene que "el narrador de Ribeyro hace reflexiones a partir de la interioridad de sus personajes" y que por ello no es behavorista, "pero tampoco claramente sicologista puesto que 
sus reflexiones manifiestamente subjetivas no ayudan a comprender a los personajes ni al mundo narrado. Al entenderlas (sus reflexiones) entendemos al narrador y no a los personajes". También sostiene que "las reflexiones subjetivas del narrador no son explicaciones propiamente dichas. Ellas no elucidan: nos ayudan más a comprender al narrador mismo que a los personajes del relato" (1984: 129) .

Obviemos la parte que corresponde a las observaciones relacionadas con la interioridad de los personajes hechas por el narrador. Debe quedar claro que no ser sicologista no es una desventaja. Ribeyro, precisamente, se aleja del tipo de narrador que lousca explicar, a la manera tradicional, a sus personajes. Lo que sí hace el narrador de Ribeyro es construir sicológicamente a sus personajes a través de la descripción de sus acciones y a través de la focalización interna. Centrémonos, por lo tanto, en "las reflexiones manifiestamente subjetivas" que nos permiten reconocer al narrador de Ribeyro como uno que, fundamentalmente y desde una densa subjetividad, doserva y que, a partir de la doservación, realiza dos tipos de movimientos: describir lo que ve y siente a su alrededor y reflexionar para sí mismo sobre lo observado. Tratemos, pues, de saber qué valores defiende implícitamente el narrador de Ribeyro en "Irmta de acreedores".

En este cuento tenemos a un narrador que describe y narra los acontecimientos a partir de una inicial posición solidaria con el protagonista, Roberto Delmar. Aunque el narrador no participa del mundo narrado, adopta los valores morales y la actitud crítica y defensiva del protagonista. No hay, por lo tanto, una separación del mundo subjetivo del narrador y el mundo que describe. Al protagonista, por ejemplo, lo llama "don Roberto", pero a los acreedores no los designa como sujetos sino como objetos, como entidades cosificadas, destacandb sus defectos físicas o caricaturizándblos, a partir de la forma en que lo hace el propio protagonista.

Al inicio del relato, cuando van 1 legando los acreedores a la tienda de don Roberto Delmar, el narrador focaliza internamente en su conciencia (Ribeyro 1985: 84) : 
Sin conocer nada de sus vidas los detestaba íntimamente. Él no era hombre de sutilezas para hacer diferencias entre una empresa y sus empleados. Para él ese hombre alto y de lentes era la compañía "Arbocó" en persona, vendedora de papel y de cacerolas. El otro hambre, porque era adiposo y parecía bien camido, debía ser la fábrica de fideos "La Aurora", en chaleco y sambrero hongo.

Luego de esta focalización, el narrador hace una acotación al diálogo que revela explícitamente su toma de posición moral, que es la misma que la de don Roberto Delmar (84) :

- Quisiera saber... -comenzó la fabrica de fideos- cuántos acreedbres han sidb citados a esta junta.

- ¡Cinco! -replicó "Arbocó", sin esperar la respuesta del encomendero¡Circo!...

Sin embargo esta posición que a primera vista, es indudablemente solidaria, se toma distante y luego crítica. Por ejemplo, después de asumir el punto de vista moral del protagonista y su defensa, el narrador dice lo siguiente (Ribeyro 1955: 85) :

En su irritación confundía la puntualidad de las citas con la de los plazos judiciales, los atributos de los hombres con los de las instituciones. Estaba a punto de inarrir en mayores enredbs...

Sonprende constatar que la inicial solidaridad con el personaje solo implicaba el manejo de la focalización intema de la narración y aunque parecía que el narrador se solidarizaba implícitamente con Delmar al asumir su punto de vista, en realidad, no era así. Destacar que la forma de cosificar a sus acreedbres es solo el resultado de la confusión que le producen "los atributos de los hombres con los de las instituciones", es reducir su indignación al caos mental por el que atravesaba en el momento de la junta.

Otro mecanismo para ironizar la figura de don Roberto Delmar es el que se ocupa de ridiculizar su forma de pensamiento. La limitada inteligencia del protagonista es graficada a través de la forma en que observa a su competidor. El narrador busca detectar en este mecanismo una forma de defensa pueril ante la amenaza de enemigo. Es cierto que la defensa de Delmar es ingenua, pero la prédica neorrealista no 
se solaza en las desventajas de los más débiles. El narrador incide en que "este era, no dbstante, un subterfugio mry fácil en el que siempre recaía" (Ribeyro 1955: 89) .

Mostrar cierta insensatez en Roberto Delmar es otro mecanismos utilizado por el narrador para configurar una personalidad desequilibrada. La escena que produce esta reacción se da cuando el protagonista, luego de escuchar el monto de la deuda total, se abstrae por un momento de la circunstancia que lo rodea y bajo el influjo del sonido de un mambo que le llega de una casa vecina, piensa (Ribeyro 1955: 93-94):

¿Por qué no se cogían de la mano él y los acreedores y Bonifacio y se iban al baile para olvidar todas esas pequeñas miserias?

Cuando empieza a negociarse la deuda para llegar a un arreglo y hay que tomar una decisión, la forma en que argumenta Delmar para defender su posición es ridícula y lo es porque, según el narrador, su inteligencia es limitada. Un hombre que no puede identificar las verdaderas razones de su fracaso y las explica por la gordura de su opositor no puede ser más que ridículo (Ribeyro 1955: 94).

Ia percepción del narrador, como se puede observar, está alimentada por una fuerte carga irónica. A veces podemos percibir que no ve al protagonista como una víctima de las circunstancias y mucho menos del sistema. Por ello lo muestra en toda su mediocridad e incapacidad para conducirse en situaciones graves.

Al examinar este cuento, James Higgins, se ha referido a que "la inhumanidad del sistema" sociceconómico está destacada por el hecho de que, a diferencia de Delmar, cuya individualidad está señalada por su identificación como don Roberto, los acreedores están identificados, no por su propio nombre, sino por el de la compañía a la que representan" (Higgins 1991: 34). En realidad, si observamos bien, no estamos frente al deseo del narrador de mostrar la inhumanidad del sistema, sino frente a la percepción del propio Delmar, que en su mente, los observa y ridiculiza como cosas o empresas. El narrador, a través de la focalización intema del protagonista sólo presenta esa percepción que, luego, él criticará cuando se refiera a la confusión que opera en la mente del propio bodeguero. 
El narrador quiere mostrar a un hombre derrotado. Con el fin de lograr ese propásito, sus esfuerzos no tienen límites; lo cual, incluso, puede revelar, en él, cierta inhumanidad. Ell tipo de derrota representada es la derrota de alguien esencialmente mediocre, no la de alguien que puede ser considerado, como lo querían los neorrealistas, víctima de las condiciones sociales. Incluso, cuando puede mostrarlo en una circunstancia en la que el protagonista siente que ha tenido una victoria moral, es decir, la salvación de su dignidad, el narrador debilita esa fe. Al personaje le es imposible sentir que, a su manera, ha logrado algún tipo de victoria. Curiosa y contradictoriamente, el narrador convierte al personaje en un hombre lúcido como para darse cuenta de que ese mecanismo defensivo solo es la manifestación de una distorsión de su raciocinio.

Otro mecanismo utilizado por el narrador, ajeno a la ortodoxia neorrealista, es el que opta por despojar al protagonista de lo que, precisamente, lo convierte a los ojos del lector en una víctima social. Vemos que la intención del narrador no es la de mostrar al protagonista como una víctima del sistema económico, sino como un mediocre incompetente que no sabe movilizarse en un sistema que a otros sí beneficia. Lo que sonprende y resulta contradictorio es que al inicio el narrador se solidarice ambiguamente con el protagonista para luego abandonarlo y que, para ilustrar los "excesos" de esta junta de acreedores, establezca en el relato dos universos marcadamente opuestos, eso sí, a la manera neorrealista.

Finalmente, el narrador da cuenta de la liquidación moral del protagonista al referir la pérdida de lo que, de acuerdo con lo narrado, se consideraba su don más preciado: la fe. En este extremo moral en el que se sitúa el personaje, el escepticismo y el desaliento han terminado por acabar, en Delmar, con cualquier escrúpulo. Declarada la quiebra, esa palabra que se extiende en su interior como una enfermedad devastadora, Delmar pierde toda posibilidad de reconciliarse consigo mismo. Así, es presentado como alguien que, incluso, no puede afirmarse en su propia dignidad, alguien en quien el permanente síntoma de la inestabilidad no puede dejar de roer lo resistente.

Sin embargo, sostengo que no debemos llegar a extremos tales como los de Peter Elmore quien afirma (2002: 52) que el protagonista 
de este cuento extrema su situación y termina suicidándose. No hay en el texto ningún indicio inequívoco de que ello pueda suceder. Ia insinuación está allí, pero es solo eso. Optar por la tesis del suicidio es empobrecer las posibilidades que abre el relato hacia el final y que hacen aún más misterioso y temible el destino del protagonista.

\section{La inhumanidad del sistema}

Una de las preocupaciones centrales de la Teoría Crítica elaborada por Adomo y Horkheimer era la de diagnosticar "crisis sociales de modo de posibilitar y alentar futuras transformaciones sociales" , (Benhabib 1994: 82). Para ellos, era importante "desarrollar una nueva teoría social y científica de la crisis para tratar con los acontecimientos históricos a los que se enfrentaban" (Benhabib 1994: 83). Eso los diferenciaría de la teoría tradicional y ese acercamiento les permitiría explicar crítica y dialécticamente el acontecer.

Son ellos los que, además, se ocupan de analizar las relaciones entre la cultura y la economía, y los efectos que esta última tienen sobre la vida síquica de los individuos.

Ia influencia del predicamento de la Escuela de Frankfurt, iniciado hacia mediados de la década de los años veinte del siglo pasado, se prolongó hasta fines de los años sesenta y tuvo en figuras como Marcuse a uno de sus filósofos más populares. Digamos, entonces, que en medio de la Segunda Guerra Mundial, son ellos los que propician la reflexión sobre el estado capitalista y su economía, hasta llegar a la crítica de la razón instrumental.

La inhumanidad del sistema capitalista ha sido el telón de fondo que los filósofos, críticos literarios y sociólogos han utilizado para explicar el comportamiento y el destino de los seres humanos en un contexto de explotación económica.

En el caso de la crítica literaria (Higgins 1991: 35) este concepto ha sido ut i lizado para ermarcar el destino de ciertos personajes de ficción vinculados con un fallido proceso de modernización en el contexto de un capitalismo incipiente y con escasos instrumentos para democratizar ese proceso. Es el caso del análisis de los primeros cuentos de Ribeyro. 
Eso es cierto, es el caso de cuentas camo "Los gallinazos sin plumas", en donde estamos frente a niños indefensos convertidos en víctimas explotadas, incapaces de escapar por sí mismos a una insoportable sumisión.

Se entiende que la inhumanidad del sistema se manifiesta no solo en las estructuras sociales que hacen imposible una convivencia respetuosa y digna, sino, y fundamentalmente, en el comportamiento inhumano de aquellos que conviven en ese sistema y son afectados y transformados permanentemente por él. Manifestaciones de esa inhumanidad podrían ser la ausencia de ayuda mutua entre los hombres, la radical indiferencia frente al débil o el abuso y la explotación i i imitada de cualquier ser humano alentada por un egoísmo inagotable e implacable. En el cuento analizado, veremos cómo la dinámica de los acontecimientos va relativizando la ausencia de ayuda mutua (que sí es presentada en el texto) y que la explotación ilimitada del más débil no es tal (en tanto se responsabiliza a Delmar de su propia desgracia) . Veremos cómo el sistema capitalista es presentado como un operador que sí permite salidas económicas a Delmar y que, a su manera, en el caso de los acreedores, se produce un proceso de humanización.

\subsection{La inhumanidad del sistema en "Ulnta de acreedores"}

Explicar una vida o un destino a partir de la inhumanidad del sistema, estableciendo una pasición solidaria con la víctima, es asumir no sólo un punto de vista crítico, sino también un enfoque neorrealista. Es entender la importancia que las condiciones desiguales e injustas de convivencia tienen en el comportamiento de lo seres humanos, de manera que la representación artística incida en la denuncia (diríamos que documental) de esa situación.

En "Junta de acreedores" la inhumanidad del sistema, tal como es observada por los críticas de la economía capitalista, se ve disminuida o amenguada por la esencial incapacidad del protagonista para adaptarse a las nuevas condiciones de un contexto en el que las víctimas no son tales, sino en cuanto resultan incompetentes para su adaptación. No hay en el cuento una insinuación de las contradicciones de un 
sistema que convierte a los seres humanos en objetos o en meras representaciones de los intereses de otros. No hay una exposición de la disfuncionalidad del sistema para, a partir de allí, desarrollar una reflexión en torno a la victimización que el sistema fomenta desde ese esencial egoísmo que promueve el capitalismo salvaje. Lo que está claramente descrito, y es aprovechado en toda su significación es la incompetencia de un comerciante cuyo fracaso es la suma de sus propios errores. Ser inepto, poco inteligente, débil y hasta ridículo, no son en el cuento consecuencias del sistema injusto que ha fomentado una personalidad de ese tipo. Son características que el narrador le atribuye al protagonista para configurarlo como el símbolo del fracaso.

En este cuento de Ribeyro ser incompetente o no estar preparado para enfrentar una situación imprevisible no deslegitima o no supone un cuestionamiento del sistema en el que presenta a sus personajes. Si uno observa bien, ese "sistema inhumano" al que se somete Roberto Delmar, le ofrece una reducción del cincuenta por ciento de la deuda (gran parte de la cual ya tiene más de un año) y facilidades para pagar, es decir, le ofrece la pasibilidad de salir adelante a partir de las leyes en las que el propio protagonista ha aceptado participar y en las que, hasta el momento de su desbalance, ha venido desarrollándose. Recuérdese que ha comprado gran cantidad de cemento para ampliar su local. No estamos, por lo tanto, frente a condiciones injustas o desiguales, ni asistimos a una expoliación del sujeto a partir de un trato desleal por parte de los que son representantes de los acreedores. En realidad, estamos frente a un comerciante cuya inteligencia (ridiculizada a la largo del relato) no es lo suficientemente eficaz para solucionar el problema de liquidez al que su propia impericia lo ha concucido.

Entiéndase bien, no sostengo que el capitalismo sea justo y mucho menos que lo sea con los débiles. Lo que sostengo es que en el relato de Ribeyro, el sistema presuntamente inhumano le brinda demasiadas oportunidades a don Roberto Delmar para salir adelante, de modo que ese sistema es casi legitimado por la ineptitud del protagonista.

Es cierto, toolos los personajes involucrados en el relato son, a su manera, víctimas de la situación en la que se encuentran. Tanto los representantes de los acreedores, convertidos en remedos humanos 
de aquello que representan comercialmente, como don Roberto, que está pagando la suma de todos sus errores, están sumidos en esa alienación que el sistema produce en los sujetos. Pero es tan personal la representación del fracaso, tan personal la nuina, tan íntima la derrota de Delmar, que es posible también explicar toda esta situación no por la llamada "inhumanidad del sistema", sino por la testarudez e incompetencia de alguien que no puede manejarse bien en los negocios y que, finalmente, se resiste obcecadamente a cambiar sus mecanismos de negociación.

Citando a Julio Ortega, Víctor Vich (2004: 10) se ha referido a la narrativa de Ribeyro como aquella que representa a un país que se moderniza sin democratizarse y que en ese violento movimiento se realiza una "exploración del cambio social pero con la notable particularidad de hacerlo al interior de resistentes prácticas que permanecen dentro de la subjetividad" . En este cuento, por cierto, es visible la confrontación del narrador con lo que Vich llama "resistentes prácticas que permanecen dentro de la subjetividad". Si optamos por la confrontación crítica de esas formas que se resisten a morir (no saber competir, sentirse víctima, pedir patéticamente más favores de los que uno merece, atribuirle al otro la responsabilidad de nuestros errores) en un contexto de modernización, convendremos en que el narrador es implacablemente irónico frente a esas resistentes prácticas y que, en el intento de criticar el anquilosado manejo que Roberto Delmar hace de sus negocios, la propuesta termina siendo más clara aún: el sistema capitalista es bueno, lo que sucede es que debemos ser menos sentimentales, más permeables al cambio y más eficientes, si es que verdaderamente queremos sentirnos dignos.

En conclusión, la forma en que se representa la inhumanidad del sistema es, en este cuento, disfuncional, si el propásito fue condenar a ese sistema a la manera neorrealista.

\section{Referencias bibliográficas}

BENHABIB, Seyla (1994) : "La crítica de la razón instrumental". En Slavoj Zizek (compilador) Ideología. Uin mapa de la cuestión. Fondb de Cil tura Económica. Buenos Aires; pp. 77-106. 
DEICADO, Wáshington (1995) : "Julio Ramón Ribeyro en la Generación del 50" . En Néstor Tenorio (editor) Jilio Ramón Ribeyro: el numor de la vida. Arteidea. Lima, 1996; pp.109-119.

EIMDRE, Peter (2002) : Ell perfil de la palabra. La dbra de Irlio Ramón Ribeyro. Fondb de Cultura Económica-Pontificia Universidad Católica del Perú. Lima.

GARCÍA ESCUDERO, José María (1970) : Vamos a hablar de cine. Salvat editores. Madrid. HIGGINS, James (1991) : Cambio social y constantes hmanas. La narrativa corta de Ribeyro. Fondb Editorial de la Universidad Católica. Lima.

KRISIAL, Efraín (1984) : "El narradbr en la dora de Julio Ramón Ribeyrd" . En Ismael P. Núrquez y César Ferreira (editores) Asedios a Julio Ramón Ribeyro. Pontificia Universidad Católica del Perú. Lima, 1996; pp. 127-148.

REIS, Carlos y Ana Cristina M. LOPES (1996) : Diccionario de narratología. Ediciones colegio de España. Salamanca.

RIBEYRO, Julio Ramón (1955) : "Junta de acreedbres". En La palabra del mudb I. Mi 7 la Batres Editorial. Lima, 1973; pp. 81-98.

ROMANGUERA, Joaquim y Homero ALSINA THEVENET (eds.) (1985) : Fuentes y cbamentos del cine. La estética. Las escuelas y los movimientos. Eolitorial Fontamara. Barcelona.

VICH, Víctor (2004) : "Julio Ramón Ribeyro o el desencanto que denuncia". En Victor Vich (presentación, selección y cronología) Cuentos y ensayos. Jilio Ramán Ribeyro. Pontificia Universidad Católica del Perú. Lima; pp. 9-13. 